NBER WORKING PAPER SERIES

THE EFFECTS OF HOURS CONSTRAINTS

ON LABOR SUPPLY ESTIMATES

\author{
Shalumit Kahn
}

Kevin Lang

Working Paper No. 2647

\author{
NATIONAL BUREAU OF ECONOMIC RESEARCH \\ 1050 Massachusetts Avenue \\ Cambridge, MA 02138 \\ July 1988
}

This study was supported in part by NSF Grant no. SES-8707422 and by Lang's Sloan Faculty Research Fellowship. This analysis is based on Statistics Canada microdata collected in 1985 for the Survey of Work Reduction. All computations on these microdata were prepared by the authors, and the responsibility for the use and interpretation of these data is entirely that of the authors. 
NBER Working Paper \#2647

July 1988

\section{THE EFFECTS OF HOURS CONSTRAINTS ON \\ LABOR SUPPLY ESTIMATES}

\section{ABSTRACT}

Almost all labor supply models are estimated under the assumption that workers are free to choose their hours. However, theory, casual empiricism and survey data suggest that many workers are not free to vary the hours within a job. Consequently, labor supply estimates based on actual hours of work may be biased. Using Canadian data on desired hours of work, we find that using actual hours causes labor supply estimates to be biased upwards but the bias is small.

Shulamit Kahn

Department of Finance and Economics School of Management 704 Commonweal th Avenue

Boston, MA 02215

\author{
Kevin Lang \\ Department of Economics \\ Boston University \\ 270 Bay State Road \\ Boston, MA 02215
}


Almost all labor supply models are estimated under the assumption that workers are free to choose their hours. In contrast there exists a wide range of theories which suggest that employment relations will specify hours as well as wages. These include implicit contract models in which workers' wages are "insured" by the firm while hours fluctuate (see Lilien and Hall 1986 and the references therein); agency and firm-specific capital models in which wages diverge from VMP in order to deter workers or firms from "misbehaving" (Lazear 1979, 1981); hedonic models with hours of a job fixed either because of the need for coordination of workers or because there are fixed "set-up" costs of working (Rosen, 1986); " efficiency wage models in which firms set long hours to capture workers' rents (Bulow and Summers, 1986), and costly bonding models in which the cost of bonding increases with hours worked (Lang 1987). In sum theory strongly suggests that the assumption that workers can freely vary their hours on a particular job is incorrect.

Nevertheless, relatively little empirical work has been devoted to labor supply models with constrained hours. Two studies have used the Panel Study of Income Dynamics data on hours constraints. Ham (1982) estimates labor supply using a sample selectivity approach to correct for bias due to some workers being underemployed (i.e. working fewer hours than desired) or unemployed. He finds that correcting the sample selection bias changes the estimated wage elasticity from -.16 to -.14 . However, this effect appears to be due primarily to the bias from unemployment. Failing to control for underemployment appears to bias the estimated wage elasticity upwards by a

'It appears that unless coordination requirements completely $\mathrm{f}$ ix hours, this model must be complemented by legal or social restrictions on firms' ability to pay workers hourly wages that decline as hours increase. 
trivial and statistically insignificant amount. Ball (1987) finds that observed behavior better accords with predictions of an intertemporal labor supply model when workers who face hours constraints are eliminated from the sample. His intertemporal labor supply elasticities are not significantly different using the constrained and the unconstrained samples, with the unconstrained sample yielding lower point estimates of this elasticity.

Two other papers have addressed tied wage/hours offers without using direct questions on hours constraints. Lundberg (1985) estimates a wage/hours hedonic locus simultaneously with a labor supply equation, finding a significant but weak effect of hours on wages." This suggests that while labor supply estimates which ignore hours constraints are biased, the bias may be small. Dickens and Lundberg (1985) develop a model in which the offer distribution and labor supply are estimated simultaneously from observed hours and wages. In contrast to the other studies discussed, they find that ignoring hours constraints significantly biases the estimated wage elasticity upwards.

While these papers represent significant advances in our knowledge, they all depend on restrictive identifying assumptions especially with respect to nonlinearities and functional form. These identifying restrictions were necessary because the data available to the authors was limited: none of the data sources used included direct information on desired hours. Thus, some of these papers (Lundberg, Dickens and Lundberg) were entirely based on data on actual hours and wages, while others also had data on the existence and direction of any hours constraints, but not the

\footnotetext{
In addition, Lundberg (1985), using panel data, finds that hours "Granger cause" wages, which lends support to the existence of a wage/hours hedonic locus.
} 
size of the constraints (Ham, Ball).

This paper is able to reduce dependence on such restrictions by directly considering desired hours of work using a Canadian survey which elicited self-reports of preferred hours of work given pro-rated salary changes. We use our measure of the divergence between actual hours and desired hours to cast light on the magnitude of the bias which results from using actual rather than desired hours in a simple labor supply model. Despite the fact that we find considerable evidence of divergence between actual and desired hours, our point estimates suggest that the degree of bias from using the former as the dependent variable is small.

I. Methods

The basic approach we adopt in this paper is kept quite simple. We assume a constant elasticity labor supply equation

$$
\text { In } h_{1}{ }^{\star}=X_{1} B+b \text { ln wage }{ }_{1}+\varepsilon_{1}
$$

where $h^{\star}$ is desired hours of work, $X$ is a vector of explanatory variables and $\varepsilon$ is an i.i.d. random error term.

Typically, we do not observe $h *$ but only $h$, actual hours. The standard regression equation is therefore

$$
\text { ln } h_{1}=X_{1} B+b \text { ln wage }{ }_{1}+\varepsilon_{1}+\mu_{1}
$$

where $\mu$ is an error term representing the deviation $\ln h$ - In $h^{\star}$. If $\mu$ is not orthogonal to the explanatory variables, OLS estimates of $B$ and $b$ will not be consistent. ${ }^{3}$ Intuitively, we expect this to bias labor supply elasticities towards zero, since actual hours are likely to be much less

${ }^{3}$ This point holds mutatis mutandis if additional econometric problems require more sophisticated estimation techniques. 
flexible than desired hours and hence less responsive to wages. Thus, assuming a positively sloped desired labor supply, we expect wages to be negatively correlated with $\mu$.

We take two approaches to evaluating the degree of bias in labor supply elasticities that use actual hours. First, we investigate whether or not $\mu$ is orthogonal to the explanatory variables in equation (2). Second, we provide direct estimates of the bias by comparing labor supply estimates using actual and desired hours for some sub-samples. We do not intend to portray our results as superior labor supply point estimates: for instance, we do not attempt to deal with nonlinearities of the budget set, the intertemporal nature of labor supply, or any other of a myriad of problems in labor supply estimates. In fact, the wage data in our data source are far from ideal for estimating labor supply equations, as will be explained below. However, our purpose is only to give a sense of the size of bias incurred when estimating an equation such as (2) based on actual rather than desired hours. We argue below that although the imperfect wage data leads to biased estimates of labor supply elasticities, it is unlikely to cause any substantial bias in the difference between labor supply estimates, and thus should not significantly detract from our estimate of the bias introduced by using actual rather than desired hours.

\section{Data}

Our data are from the Survey of Work Reduction (SWR) which was collected as a written supplement to the Canadian Labor Force Survey (the equivalent of the U.S. Current Population Survey) in June 1985. The questions in this survey pertaining to desired work hours are included in 
the Appendix to this paper. These questions are much more specific than either of the two major U.S. surveys on hours constraints, the Panel study of Income Dynamics (PSID) and the May 1985 Current Population Survey (CPS), which do not elicit data on the actual numbers of desired hours. Moreover, long introductions to the questions on desired hours of work reduction (see Appendix) were designed to ensure that respondents understood these questions, and especially that they understood that the hypothetical hours reductions or increases would imply prorated salary changes.4

Despite the considerable effort which Statistics Canada put in to ensuring that the data measure what they are intended to measure, there is ample evidence of imperfections in the data as in all surveys. About $2 z$ of respondents both wanted to work more and to work less. In our analysis, these respondents were dropped from the sample.

Other people were dropped from the sample because we could not ascertain their desired number of hours.'s Specifically, those with NA's to the questions about how much they would prefer their hours to change were excluded. In addition, a substantial fraction of respondents said that the reason they did not want to work fewer hours was that it was not possible on their job. Respondents who did not want to work more hours and who responded that the reason that they did not want to work fewer hours was

'In contrast, the PSID questions' wording would leave salaried workers uncertain about whether hypothetical hours increases would be accompanied by any sataries changes.

In addition, outliers who replied that they wanted to work more than 72 hours per week were assumed to have miscalculated, and were replaced with 72 desired hours per week. Note that the maximum actually worked in the sample was 65 hours per week, and the arbitrarily chosen 72 hours was 1 hour more per day than this maximum. 
because it was not possible on their jobs were also eliminated from the sample because it was impossible to determine their desired hours. This removed roughly one-eighth of the observations from the sample.

A final concern arises about whether or not the respondents interpreted the questions as intended, despite the questionnaire's elaborate introduction. The survey posed a series of follow-up questions about how important various factors were in causing the respondent to want to work fewer hours. About half of respondents who said they wanted to work fewer hours said that a very or somewhat important reason for their wanting to work fewer hours was to reduce the probability of being laid-off. clearly, this reason for wanting to work less does not correspond to our concept of wanting to supply fewer hours at the going wage. Moreover, in the introduction to the survey respondents had been explicitly told to assume that the hypothetical hours reductions would not affect their job security or job situation in general.

However, it is unclear that the implied importance of layoff avoidance should be taken a face value for two reasons. First, even those respondents who claimed that not getting laid-off was an important reason for wanting to reduce hours generally gave a number of other important reasons for wanting to reduce hours. Secondly, the survey was preceded by a prologue which explained that the reason the survey was being conducted was to examine the possibility of reducing unemployment by having workers voluntarily reduce their hours of work. This might have made the possibility of unemployment salient in their minds when asked specifically whether reducing the probability of being laid off was a factor.

Despite these concerns, the data used here appear to be the only 
measures of desired hours available. Moreover, the wording of the SWR questions and their introductions generally introduce fewer ambiguities than the other surveys' questions.

The wage data in the SWR pose much more serious problems. The survey does not collect specific figures for wages or income. Instead, respondents are asked to place their (total) own income into one of seven bracketed ranges. Translating the categorical income variable into a continuous wage variable is by no means straight-forward. First of all, the income figures must be divided by hours. The SWR asked questions both on usual weekly hours and hours last week. As is often the case, it is unclear whether usual weekly hours includes "normal" overtime. We therefore experimented with both "hours" variables. Second, the decision had to be made whether and how to translate the brackets into a continuous variable. To ascertain how much information was lost by constructing a continuous index from this categorical data, we compared specifications for nonunion men including six income dumy variables to specifications using one of two continuous income variables, the first using midpoints of the brackets and the second using a simple index where 1 was the lowest wage category, 2 the second, etc."

Resulting $F$ tests suggested that little information was lost by treating the categorical variable as continuous. Of the two continuous income variables, the simple index had more explanatory power. Results were similar whether hours were measured as usual hours or desired hours. We therefore estimated

We limited experimentation to nonunion men to lessen any problems of "data mining."

'These measures are not very different except for scale, since all income brackets were equal sized ( $\$ 10$ thousand Canadian) except the lowest $(\$ 0-\$ 20$ thousand) and the highest $\$ 70+$ thousand (assigned a midpoint of $\$ 80$ thousand). Scale is irrelevant since all specifications were in log form. 
the $\log$ wage as $\log$ (income index/hours last week).

Bracketed data reduces the accuracy of our estimates, but does not introduce inconsistency. However, other aspects of the constructed wage variable do introduce inconsistency. Most significant is the fact that hours are included in the denominator which will cause a spurious negative correlation between the wage variable and the error term in equation (2). In addition, income includes non-labor income, which may be correlated with the error term.

To mitigate the latter two problems, we use instrumental variables with twenty-eight occupation dummy variables as instruments for wage. To the extent that occupation affects hours only via the wage, inconsistency is eliminated. However, occupation dummies are not ideal instruments for wage, since there is likely to be some correlation between occupation and hours (both desired or actual) not due to wage differences. (For instance, the inherent propensity towards workaholism might belong in labor supply equation but is, of course, unmeasurable. However, workaholism may be correlated with occupation.) This correlation between occupation and hours implies that instrumented wages, a linear combination of the occupation dumies, is still somewhat negatively correlated with the error term. Thus, using occupation to instrument wages is likely to reduce but not eliminate the bias due to hours in the denominator of the wage measure. Partially because of the lack of perfect instruments for wage, we also consider reduced form labor supply equations in which wages have been eliminated.

The bias is further reduced by concentrating on the results of equations where $\mu$, the difference between actual and desired hours, is the dependent variable. Asymptotic bias will occur only to the extent that 
over- or under-employment in particular occupations is correlated with the average hours in those occupations for reasons unrelated to wages.

Intuitively, there seems no reason to expect such a correlation.

On the other hand, the bias from including nonlabor income with labor income should be solved by instrumenting wages with occupation, since occupation is unlikely to be significantly correlated with nonlabor income.

In the case of women, almost all respondents indicated that they were in the first or second income category. As a consequence almost of the variation in estimated wages would be due to variation in hours, and it is impossible to estimate the labor supply-wage relationship. Therefore, for women, only reduced form equations excluding wage are reported.

The remaining variables used in this study are URBAN, a dummy variable equal to 1 if the individual lives in an urban area, MARRIED, a dummy variable equal to 1 if the individual is presently married, AGE measured in 10 year intervals, CHILDREN, the number of children in the household under age fourteen', four dummy variables for education levels, no education beyond primary school being the left out variable and UNION, a dummY variable if the worker is covered by a collective bargaining agreement. We limited the sample to individuals who were employed in the private nonagricultural sector who were age 25-64 and for whom a complete set of data were available.

\section{Results}

The responses indicate considerable divergence between actual and

${ }^{B}$ However, if there were more than three children in any one category (five or less, 6-11, 12-14), the survey recorded only three children for that age group. 
desired hours. Just over half of respondents would like to work a different number of hours at their present wage. Of these, over two-thirds would like more hours. The difference between the proportion wanting to work more and those wanting to work less is somewhat more pronounced for nonunion men than it is for union men or women. (See Table I) of those expressing a preferred number of hours, the average nonunion male worker wanted to work 3.8 more hours than he actually worked, while on average union male workers and women workers wanted to work 3.0 and 3.7 more hours, respectively.

Responses to the question about wanting to work more, fewer or the same number of hours appear to be somewhat but not qualitatively different from those obtained in the United States CPS in May 1985 (Shank 1986). In the CPS, on average $64.8 \%$ of wage and salaried workers wanted to work the same, $7.5 \%$ wanted to work less, and $27.7 \%$ wanted to work more. Thus, in Canada, it seems that a somewhat lower proportion of workers are satisfied with their present hours, and that of those who would like to change their hours, in Canada a somewhat higher proportion want to work fewer hours. We can only speculate whether these differences are due to the wording of the questions in the surveys in the two countries or to actual U.S.-Canada labor market differences.

As discussed in section I, labor supply estimates using the log of actual hours $h$ rather than desired hours $h$ * are likely to be biased only if the deviation between $\ln h *$ and in $h$, or $\mu$ in equation (2), is orthogonal to the explanatory variables in the labor supply equation. Table II, columns $(1)-(3)$, gives the results from regressing $\mu$, the difference between log actual hours worked and log desired hours worked, on exogenous variables besides wage typically included in labor supply equations, while 
columns (4) and (5) give the results including wage (instrumented) as well. Since the wage variable cannot be constructed for women, only the reduced form estimates in Table II allow us to compare all three demographic groups, union men, nonunion men and women. For each of these three groups the explanatory variables in columns (1)-(3) are jointly significant although their explanatory power is small.

Table II indicates that higher wages increase the extent to which individuals work more than they wish to. ${ }^{9}$ Thus, in columns (1) and (2) those variables which raise wages also increase $\mu$, the $\log$ (actual hours/desired hours), consistent with the positive significant coefficients on wage in columns (4) and (5). Nevertheless, the magnitude of this wage effect is quite small and is statistically insignificant in the case of union men. The small positive point estimates of the effect of wage on $\mu$ implies that labor supply elasticities for men are slightly biased upwards: i.e., the true labor supply curve based on desired hours (equation 1 ) is steeper than the labor supply equation based on actual hours (equation 2), since low wage workers tend to desire to work (on average) more extra hours than do high wage workers. This bias is in the opposite direction from that expected a priori.

For women, the Table II coefficients generally tell a similar if less consistent story: most but not all variables which raise wages also tend to increase $\mu$, and thus decrease underemployment, the tendency to want to work more. This is particularly clear in the case of education. The exceptions are the "married" variable, which is generally negatively correlated with

Additional tabulations (not shown) demonstrate that this reflects both an increase in the fraction wanting to work less and a decrease in the fraction wanting to work more as wages rise. 
wages for women but here, decreases underemployment and age which has no effect.

Age is the only other coefficient which is statistically significant for both nonunion and union men when wage is included in the equations. overemployment (actual minus desired hours) increases with age. To the extent that age proxies tenure, this is the opposite of what is predicted by the Lazear (1979, 1981) agency model where wages exceed VMP later in the work relation to deter cheating, so that more senior workers wish to work more hours than the contract permits. On the other hand, the finding is consistent with specific-capital models in which workers and firms share the investment so that VMP exceeds the wage for senior workers. ${ }^{\circ}$

To check whether the Table II results are reasonable despite the imperfect wage measure and instruments, Table III reports the labor supply equations underlying the last two columns of Table II. Elasticities from the labor supply equations of log(actual hours) are close to zero and in the general range of unsophisticated labor supply estimates using better wage data reviewed in Killingsworth (1983). This suggests that the downwards bias on the elasticity estimates from using the poor wage measure is not too great. It is likely that problems due to the poor wage measure are very small even in the labor supply equations, where we would expect its effect to be much greater than in the equations of $\log ($ actual/desired hours). This therefore lends credence to our estimates in Table II.

${ }^{10}$ For a more detailed consideration of this point using U.S. data see Kahn and Lang (1987). 
IV. Conclusion

Despite our finding that the majority of workers desire to work a different number of hours from that which they actually work and that a strong majority of these are underemployed, our findings generally suggest that the implications for studies of labor supply are fairly modest. The bias from using actual rather than desired hours is on the order of .05 or .1. This small bias is consistent with Ball (1987), Ham (1982) and Lundberg (1985).

Moreover, in contrast to what might have been expected, labor supply elasticities appear to be lower using desired rather than actual hours. If hours constraints simply made workers' actual hours inflexible compared to their desired hours, for instance if hours are fixed at forty hours per week, we would expect desired hours to respond more sharply to wage differences than actual hours. However, the bias observed is in the opposite direction. The bias results from a positive correlation between $\mu$ $[\log ($ actual/desired hours)] and wages that results from fewer higher wage workers than lower wage workers wanting to work more, more wanting to work less. This finding calls for further theoretical and empirical study consideration. It implies that a positively sloped relationship between actual hours and wages may, at least partially, be the result of employers preferring low wage workers to work fewer hours than desired while preferring high wage workers to work additional hours, rather than the result of labor supply responses. 
REFERENCES

Ball, Laurence, "Intertemporal Substitution and Constraints on Labor Supply: Evidence from Panel Data," mimeo, 1987.

Bulow, Jeremy I. and Summers, Lawrence H. "A Theory of Dual Labor Markets with Application to Industrial Policy, Discrimination, and Keynesian Unemployment," Journal of Labor Economics, 4 (July 1986): 376-414.

Dickens, William $\mathrm{T}$. and Shelly Lundberg, "Hours Restrictions and Labor Supply," NBER Working Paper No. 1636, 1985.

Ham, John C., "Estimation of a Labor Supply Model with Censoring Due to Unemployment and Underemployment," Review of Economic Studies, 49 (July 1982): $335-54$.

Killingsworth, M.R. Labor Supply. New York: Cambridge University Press, 1983.

Lang, Kevin, "The Impossibility of Efficient Bonding Contracts or Why Was There Mandatory Retirement?" NBER Working Paper No, ????.

Lazear, Edward, "Agency, Earnings Profiles, Productivity and Hours Restrictions," American Economic Review, 71 (September 1981): 606-20. , "Why Is There Mandatory Retirement?" Journal of Political Economy, 87 (December 1979): 1261-84.

Lilien, David M. and Robert E. Hall, "Cyclical Fluctuations in the Labor Market," in Orley Ashenfelter and Richard Layard, Handbook of Labor Economics Volume II. Amsterdam: North Holland, 1986.

Lundberg, Shelly, "Tied Wage-Hours offers and the Endogeneity of Wages," Review of Economics and Statistics 1985:405-410.

Rosen, Sherwin, "The Theory of Equalizing Differences," in Orley Ashenfelter and Richard Layard, Handbook of Labor Economics Volume I. Amsterdam: North Holland, 1986: 641-692.

Shank, Susan E. "Preferred Hours of Work and Corresponding Earnings," Monthly Labor Review, 109 (November 1986): 40-4. 


\section{APPENDIX}

The question about reduced work hours was preceded by the following preamble:

"The following questions are about working less time for less pay. Assume that you would lose one hour's pay for each hour that you no longer work. Put another way, you would lose $5 \%$ of your pay if you work $5 \%$ less time. When you are answering the question, assume that your job situation stays the same. Your job security would not be affected. You would not jeopardize your chances for promotion or pay raises. You wouldn't lose your pension or other benefits."

The first question was:

"In the next two years, would you take a cut in pay if you received more time of $f$ in return?"

Those who answered "no" were asked "Why not?" with reply categories "Can't afford it," "Like my hours now," "Not possible in my job," and "Other reason."

Those who answered "yes" were told:

"Think about how much of your pay you could afford to give up to work less time. Remember, for every hour less you work, you would lose one hour's pay. Before answering the next question, here are some figures to help you: A week of $f$ is about $2 \%$ of a full work year (and $2 \%$ of your pay); two weeks would be 48 ; three weeks would be 68 . A half hour less per day all week long for a full work year is about 68 of your time and pay; one hour a day would be 12\%; two hours a day would be $24 \%$. One day off every week all year long is about 200 of a full work year (and $20 \%$ of your pay); two days of $f$ would be 408 ; two and a half days would be $50 \%$. If you worked for 4 years at reduced pay in order to have the fifth year off, you would be reducing your pay by $20 \%$. Use the chart below to help you think about these figures."

A chart relating percent pay cuts to dollar cuts for different salary levels followed.

Respondents who had answered "no" to the first question were then asked

"What percent of your pay would you give up to have more time of $f$ ?"

All respondents were asked:

"If you continue to be paid at the same rate of pay that you are now, would you work more hours for more pay?"

Respondents who answered "yes" were then asked:

"How many more hours per week would you want to work?" 


\section{TABLE I}

DESIRED HOURS OF WORK RELATIVE TO ACTUAL WORK

Nonunion Men

WANTS MORE

SAME

WANTS LESS
40.6

45.5

13.8

\section{Women}

32.0

51.1

16.9 
TABLE II

DETERMINANTS OF LOG (ACTUAL HOURS/DESIRED HOURS)

T-statistics are in parentheses

\section{Reduced Form Estimates}

(1)

Non-Unton Men Unton Men

\begin{tabular}{|c|c|c|c|c|c|}
\hline URBAN & $\begin{array}{l}0.010 \\
(1.1)\end{array}$ & $\begin{array}{l}0.007 \\
(0.6)\end{array}$ & $\begin{array}{l}0.016 \\
(1.3)\end{array}$ & $\begin{array}{r}-0.011 \\
(1.0)\end{array}$ & $\begin{array}{l}0.003 \\
(0.2)\end{array}$ \\
\hline MARRIED & $\begin{array}{l}0.040 \\
(3.4)\end{array}$ & $\begin{array}{l}0.003 \\
(0.2)\end{array}$ & $\begin{array}{l}0.035 \\
(2.7)\end{array}$ & $\begin{array}{l}0.028 \\
(2.2)\end{array}$ & $\begin{array}{r}-0.001 \\
(0.0)\end{array}$ \\
\hline AGE $/ 10$ & $\begin{array}{l}0.028 \\
(6.3)\end{array}$ & $\begin{array}{l}0.023 \\
(3.5)\end{array}$ & $\begin{array}{r}-0.003 \\
(0.4)\end{array}$ & $\begin{array}{l}0.019 \\
(3.7)\end{array}$ & $\begin{array}{l}0.020 \\
(2.8)\end{array}$ \\
\hline (SOME) $\mathrm{HIGH}$ SCHOOL & $\begin{array}{l}0.033 \\
(2.5)\end{array}$ & $\begin{array}{l}0.041 \\
(2.6)\end{array}$ & $\begin{array}{l}0.020 \\
(0.9)\end{array}$ & $\begin{array}{l}0.010 \\
(0.7)\end{array}$ & $\begin{array}{l}0.031 \\
(1.8)\end{array}$ \\
\hline SOME POST-SECONDARY & $\begin{array}{l}0.033 \\
(1.9)\end{array}$ & $\begin{array}{l}0.039 \\
(1.5)\end{array}$ & $\begin{array}{l}0.043 \\
(1.6)\end{array}$ & $\begin{array}{l}0.007 \\
(0.3)\end{array}$ & $\begin{array}{l}0.024 \\
(0.8)\end{array}$ \\
\hline POST -SEC. DIPLOMA & $\begin{array}{l}0.039 \\
(2.5)\end{array}$ & $\begin{array}{l}0.061 \\
(2.8)\end{array}$ & $\begin{array}{l}0.047 \\
(2.0)\end{array}$ & $\begin{array}{r}-0.007 \\
(0.3)\end{array}$ & $\begin{array}{l}0.043 \\
(1.6)\end{array}$ \\
\hline UN IVERS ITY & $\begin{array}{l}0.071 \\
(4.5)\end{array}$ & $\begin{array}{l}0.100 \\
(3.6)\end{array}$ & $\begin{array}{l}0.086 \\
(3.1)\end{array}$ & $\begin{array}{l}0.007 \\
(0.3)\end{array}$ & $\begin{array}{l}0.077 \\
(2.3)\end{array}$ \\
\hline CHILDREN & $\begin{array}{r}-0.004 \\
(0.9)\end{array}$ & $\begin{array}{r}-0.002 \\
(0.2)\end{array}$ & $\begin{array}{r}-0.020 \\
(3.1)\end{array}$ & $\begin{array}{r}-0.007 \\
(1.6)\end{array}$ & $\begin{array}{r}-0.003 \\
(0.4)\end{array}$ \\
\hline UNION & - & - & $\begin{array}{l}0.045 \\
(3.3)\end{array}$ & & \\
\hline LOG WAGE & - & - & - & $\begin{array}{l}0.091 \\
(4.0)\end{array}$ & $\begin{array}{l}0.045 \\
(0.4)\end{array}$ \\
\hline $\mathrm{R}^{2}$ & 0.032 & 0.022 & 0.015 & & \\
\hline $\begin{array}{l}\text { Mean of dependent } \\
\text { Variable }\end{array}$ & -0.081 & -0.067 & -0.110 & -0.081 & -0.067 \\
\hline $\mathrm{N}$ & 2239 & 1267 & 2793 & 2239 & 1267 \\
\hline
\end{tabular}

\section{Estimates*}

(4)

(5)

Non-Un. Men Un. Men

$0.011 \quad 0.003$

$0.028 \quad-0.001$

$0.019+020$

$\begin{array}{ll}0.019 & 0.020 \\ (3.7) & (2.8)\end{array}$

$0.010 \quad 0.031$

$0.007 \quad 0.024$

$-0.007 \quad 0.043$

$0.007 \quad 0.077$

$-0.007 \quad-0.003$ . 
TABLE III

INSTRUMENTAL VARIABLES ESTIMATES OF LABOR SUPPLY EQUATIONS

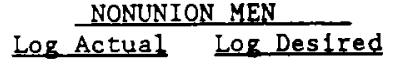

LOG WAGE

URBAN

MARRIED

AGE $/ 10$

(SOME) HIGH SCHOOL

SOME POST-SECONDARY

POST-SEC. CERTIFICATE 0.001

$-0.024$

CHILDREN
0.011

$(0.5)$

$$
0.014
$$

$(0.5)$

$(0.0)$

$(0.8)$

$-0.045$

$(1.5)$

$-0.009$

$(0.6)$

0.028

(1.7)

$-0.027$

(4.1)

0.001

$(0.0)$

0.007

$(0.3)$

0.007

$(0.3)$

$-0.032$

(1.0)

0.003

$(0.5)$

0.010

(1.7)

UNION MEN

\section{Log Actual Log Desired}

$\begin{array}{lr}0.016 & -0.029 \\ (0.4) & (0.6)\end{array}$

$-0.037$

$-0.040$

(2.4)

$(2,6)$

0.066

0.067

(2.9)

(2.9)

0.006

$(0.6)$

$-0.014$

(1.7)

0.014

$-0.018$

(0.6)

(0.8)

$-0.045$

(1.2)

$-0.069$

(1.9)

0.022

$-0.021$

$(0.7)$

(0.6)

0.060

$-0.018$

(1.4)

(0.4)

0.001

$(0.2)$

0.003

$(0.4)$

T-statistics in parentheses.

First-stage regressors include all explanatory variables except log wage plus 28 occupation dummy variables. 